\title{
Fundamentals Of Interactive Storytelling
}

\author{
Interaktif Hikayeciliğin Temelleri
}

\author{
Dr. Barbaros Bostan \\ Yeditepe University, Information Systems and Technologies Department, TURKEY \\ bbostan@yeditepe.edu.tr \\ Dr. Tim Marsh \\ James Cook University, Department of Information Technology, AUSTRALIA \\ tim.marsh@jcu.edu.au
}

\begin{abstract}
The focus of interactive storytelling should not only be on the attributes of the technology or characteristics of the medium, such as the AI techniques, planning formalisms, story representations, etc. but also on the computer-mediated communication processes, such as the relatedness of transmitted messages with previous exchanges of information, the number of attributes to be manipulated by the player, or the level of player control on the messages. This article argues that an approach to maximize player enjoyment in a computer game is to customize/personalize the gaming experience and the associated computer-mediated communication processes. To this aim and to provide answers to "how" and "what" should be customized, first the problematic notions of interactivity are explored and then the discussion is framed in the context of interactive storytelling systems. Secondly, table-top role-playing games (RPGs) - the live counterpart of computerized interactive storytelling systems - were analysed in an attempt to find "what" to customize. In particular, the article focuses on the Dungeon Master whose role in co-ordinating human-to-human communication process of interactive storytelling provides valuable insights into how to handle the humanto-machine/game communication process. Finally, the article proposes a framework to explain "how" to customize for maximum player enjoyment and optimal game experience within an interactive storytelling system.
\end{abstract}

Key Words: interactive storytelling, gameplay experience, role-playing games

\section{ÖZET}

Etkileşimli hikayecilik sistemleri sadece teknolojinin niteliklerine veya yapay zeka teknikleri, planlama kuralları, hikaye temsili gibi iletişim ortamının karakteristik özelliklerine odaklanmamalıdır. İletilen mesajların önceki mesaj alş̧verişleriyle ilişkisi, oyuncu tarafından manipüle edilen nitelik sayısı veya oyuncunun mesajlar üzerindeki kontrolü gibi bilgisayar ortamln iletişim süreçleri de teknik bileşenler kadar önemlidir. Bir bilgisayar oyununda kullance memnuniyetini arttırmantn yolu oyun deneyimini ve ilgili bilgisayar ortaml iletişim sürecini kişiselleştirmekten geçmektedir. Bu amaca ulaşmak ve 'neyin' 'nasıl' kişiselleştirilmesi gerektiğini göstermek için, bu makale öncelikle etkileşim kavramının sorunların tartışmakta, ardından aynı bağlamda etkileşimli hikayecilik sistemlerini incelemektedir. Masaüstü rol yapma oyunlarından yola çıkarak 'neyin' kişiselleştirilmesi gerektiğini inceledikten sonra bir motivasyon taslağı ortaya atarak kişiselleştirmenin 'nasıl' yapılması gerektiğini ifade etmektedir.

Anahtar Kelimeler: etkileşimli hikayecilik, oyun deneyimi, rol yapma oyunları 


\section{COMPUTER GAMES AS NEW MEDIA}

The communication metamorphosis, the emergence of cyberspace, and the convergence of intrapersonal, interpersonal and mass communication started with the Internet which was opened to public use in the 1990s but video arcade games have entered our lives as a popular media during the 1980s bringing the social debate around their harmful influences with them. Heim (1998) stated that the cultural terrain of cyberspace is made up of paradoxes, the computerized space offers an unrestricted freedom of expression and personal contact with far less hierarchy and formality but it increasingly eliminates direct human interdependence by narrowing the quality of the human encounter. According to the Internet paradox hypothesis (Kraut et al. 1998; Kraut et al. 2002) since some researchers focus on the negative effects of it while others support the positive side of the debate; the highly personalized effects of its usage cannot be generalized to everyone. Computer gaming has the same paradoxical nature, game playing is a personalized experience with varying effects specific to every player. Nevertheless, the computer or the gaming console adds a layer of technology between communication partners and the multi-directional communication process should be evaluated as a computer-mediated communication (CMC).

Computer games are a new mediated and mediating world in which users learn how to flow seamlessly between the virtual and the actual and they are by their very nature interactive (Dovey and Kennedy, 2006). According to Rogers (1951) new media environments have three common characteristics: demassification, asynchronicity and interactivity. Messages are no longer transferred to large groups of people as homogenous content; unique and personalized messages are transferred to users in a heterogeneous mass. Sending messages and receiving them do not need to be synchronous processes. Anyone can transfer any knowledge anytime; and the response will likely be transferred when the respondent desires. Although single-player computer games provide homogenous messages in the form of packaged content to game players, multi-player games conform to the demassification hypothesis by providing a unique and personalized gaming experience. The asynchronicity of Internet-based communication offers new possibilities for information exchange but computer gaming is a synchronous process; players can play the game anytime they want but once they started playing it, they expect immediate responses to their actions. As the system responds in some way to every player choice, the action-outcome unit of a choice defines the meaning that emerges in a game (Salen and Zimmerman, 2003). And the third and the most debated characteristic of new media is interactivity.

\subsection{INTERACTIVITY AS RELATEDNESS OF MESSAGES}

Interactivity is not unique to new media but is generally considered to be a central characteristic of it (Lievrouw and Livingstone, 2002). Researchers often focus on the ambiguity of the concept, conceptualization difficulties, and overuse of the term, because various fields defined interactivity from different perspectives and associated it with different terms: synchronicity, control, rapidity and speed, participation, choice variety, 
directionality, hypertextuality, connectedness, experience and responsiveness (Rafaeli and Ariel, 2007). In a gaming environment, although it is being overshadowed by the attributes of the technology or characteristics of the medium, interactivity is a product of the computer mediated communication process and an outcome of player actions. According to Rafaeli (1988), interactivity is an under-defined concept that has little consensus on its meaning and it is not located in the features of the medium or user perceptions but in the relatedness of transmitted messages with previous exchanges of information where sender and receiver roles become interchangeable. In this sense, messages transmitted by a computer game are related with the previous exchanges of information or the former actions of the player, although the complexity of this relatedness varies from simply keeping track of game scores to interactive storytelling systems that analyze player actions throughout the game for a customized experience.

\subsection{INTERACTIVITY IN VIRTUAL ENVIRONMENTS}

Video games provide an extraordinary kind of intimacy with machines where players enter into a virtual environment of infinite possibilities, experience altered states of consciousness and become absorbed in what is happening onscreen (Turkle, 1984). According to Steuer (1992), interactivity in virtual environments is composed of three elements: speed, range and mapping. Speed is the response time of the virtual world; range represents the number of attributes that can be manipulated by the user; and mapping is a function of the types of controllers used to interact with the mediated environment. Computer games aim to provide instant feedback to player actions but the response time usually depends on the configuration of the personal computer if it is a PC game and on the bandwidth of player's Internet connection if it is an online game. The range of attributes that can be manipulated by the player greatly varies, from the movement/rotation of simple objects in a Tetris game to massive multi-player gaming environments with thousands of objects and players to interact with. The mapping or the controllers used to interact with the game ranges from standard keyboard or mouse for PC games and gamepads for consoles to specialized input devices such as joysticks, racing wheels or wireless remote pistols. The Wii remote has even drawn the attraction of academic research for the special interaction form it provides (Schreiber et al. 2009).

\subsection{INTERACTIVITY AS A COGNITIVE PROCESS}

Sellers (2006) brought a brand new perspective to our notion of interactivity by defining four different levels of it that lead from perceptual, cognitive and psychosocial processes. Perceptual and physical interactivity comprises of the reactions humans give to physical stimuli, especially to bright colors, flashes, moving images, rhythmic or explosive sounds, and to specific proportions in form and color. Game players are also attracted by these pleasurable stimuli and they seek variety in these sensuous impressions. Short-term cognitive interactivity incorporates tasks that involve short-term memory and emotional focus. They combine together to form longer-term goals where planning and strategy come into play to define long-term cognitive interactivity. In this regard, computer gaming can be defined as a series of short-term cognitive interactions to reach a longer-term 
cognitive goal: the completion of the game or the mission of the protagonist. In a computer game, micro choices are moment-to-moment choices of a player; the way these micro-choices fuse as a long-term strategy defines the macro level of a choice (Salen and Zimmerman, 2003). And social interactivity is both an internal and an interpersonal process that becomes more important if players have persistent identities and are able to affect the game state together.

\subsection{THREE LEVELS OF INTERACTIVITY}

With historical parallels that pre-dated new media, the three levels of interactivity identified by researchers are user-to-user (interpersonal), user-to-content (user-todocuments) and user-to-system (user-to-computer) interactivity (Szuprowicz, 1995; Jensen, 1998; McMillan, 2002). User-to-user interactions are classified into four groups (monologue, feedback, responsive dialogue and mutual discourse) according to the level of receiver control on the messages and the direction of communication. User-todocuments interactions are classified into four groups (packaged content, content-ondemand, content exchange and co-created content) based on the level of receiver control on the messages and the nature of the audience. User-to-system interactions are classified into four groups (computer-based interaction, human-based interaction, adaptive interaction and flow) according to the center of control and the nature of the interface. Ideally, communication should be two-way, receiver control over messages should be high, audience should be active, humans should be the center of control and interface should be transparent. Of course, no such system that incorporates all these elements exists, but it should not be forgotten that communication technologies are constantly evolving and transforming.

User-to-user interaction, which is mediated through one or more of the five senses, primarily composes of verbal and non-verbal communication forms such as gestures, poses, facial expressions, etc. From a computer gaming perspective, it takes two different forms: player-to-player interactions experienced in multi-player environments and the information exchange between the player and a synthetic agent or a non-player character (NPC). Player-to-player interactions, which enable communicators to have more control over their experience beyond the constraints of time and geography, can be classified as mutual discourse where the sender and receiver roles become nearly indistinguishable. On the other hand, player-to-NPC interactions in computer games can take different forms such as monologue, feedback or responsive dialogue. The interaction level depends on the believability and the AI capabilities of the agent. Although it may seem strange at first, players may attribute human characteristics to virtual agents. The more believable and realistic these characters and their behaviors are, the more human-like the communication process becomes.

In terms of user-to-content interactivity, traditional computer games are usually shipped to online or brick and mortar stores in the form of packaged content. Online gaming platforms like Games for Windows or Xbox Live provide content-on-demand, allowing users to purchase games or game add-ons, to gain and keep track of their achievements 
(gamerscore) in order to display their progress and prowess to the community. Content exchange can be experienced in computer games that provide special tools or scripting languages to their players. Players can use these tools or scripting languages to modify the existing game or to create new chunks of content, both of which are usually shared on community websites. Modifications change the gameplaying process by altering the game mechanics, the virtual environment, the appearance and behavior of 3D objects and virtual characters. And finally, interactive storytelling refers to gaming environments where real-time feedback collected from the players is used by the game engine to continuously modify the content as it is being delivered. Although the player is passively providing a feedback of his/her preferences and play style while actively playing the game, these systems can be classified as being closest to co-created content.

The study of user-to-system interactivity or Human-Computer Interaction (HCI), which aims to improve the interactions between users and computers, is not only concerned with hardware and software but is also the intersection of several fields of study such as psychology, sociology, cognitive science, human factors, interface design, etc. Today's computer games can be classified as computer-based interaction where the player makes his/her selections from the presented information. The interfaces used to interact with a computer game (personal computers, gaming consoles, gamepads, etc.) are usually not transparent but apparent. Interface transparency can be experienced in immersive 3D environments where head-mounted displays, sensing gloves or other specialized equipment are used to block the sensations from the real world and to help the user focus on the sensations of the virtual. But it can also argued that, regardless of the transparency of the interface, our minds won't really want to do the work of separating media from reality if the media image is pleasant or motivating at a deep psychological level (Castranova, 2007). This is a reasonable explanation since some players loose themselves in the gaming environment and experience the flow state described as activities that provide a sense of discovery, a creative feeling of transporting the person into a new reality or previously undreamed-of states of consciousness (Csikszentmihalyi, 1990). Interactions with the virtual world (travelling, exploring, etc.) and the 3D objects (weapons, armour, etc.) are also user-to-system interactions.

\section{CMC COMPONENTS OF GAMEPLAYING}

\subsection{VIRTUAL COMMUNITIES}

Through CMC, people may feel community (having a sense of sharing and commonality) and immediacy (a feeling of closeness, an emotional proximity) in an online environment, even if they do not communicate face-to face (Shedletsky and Aitken, 2004). Videogame play also does not take place in an isolation that renders players socially withdrawn and inept, but is frequently located in various social contexts that may include friends, family or other gamers through participative communication (Newman, 2008). Examples of these social contexts are multiplayer gaming, post-viewing/playing talk, tip or strategy sharing, going through FAQ lists, trailers, teasers, previews, reviews or footage of gameplay published in developer websites or online gaming communities, participating in forums 
to share their gaming experience with like-minded individuals, and visiting modding communities to download/share content. These websites, forums and mod repositories create virtual communities for gamers. Members of virtual communities have a sense of belonging to a group that maintains its own norms and they experience the dimensions of a sense of virtual community defined by Blanchard and Marcus (2004): recognition of members, identification of self and others, exchange of support, relationship with specific members and emotional attachment.

\subsection{MULTIPLE SELVES}

For many people, what is being pursued in the video game is not just a score, but an altered state of mind that allow players to transform into someone imaginary (Turkle, 1984). Players can experiment with their identities and switch back and forth between different personalities continuously. The idea that individuals possess multiple selves/multiple identities has long been discussed in psychology and what Rogers (1986) defined as 'true-self' is mainly comprised of the unexpressed qualities of a person. Singleplayer computer games provide the opportunity to express this true-self without the fear of disapproval by taking away the expectations, obligations or constraints of the society. For example, it is even possible to play an assassin of Renaissance Italy in Assassin's Creed $2^{1}$ or the villainous apprentice of Darth Vader in Star Wars: Force Unleashed ${ }^{2}$. Although multi-player games create communities with their own norms and rules, the anonymity still gives the player the freedom to express one's hidden facets of personality or to experiment with them. But of course, regardless of multiplayer capabilities of the game, this true-self expression is usually constrained by the game mechanics. For example, one can not express his/her caring and sensitive nature if the game does not provide the dialogue options or the interaction techniques to represent them.

\subsection{IMPRESSION MANAGEMENT}

CMC provides a more controllable and fluid from of impression management and with the introduction of multiplayer 3D video games, impression management in online environments has evolved into a special form of self-representational freedom: the power to customize the visual appearance of the virtual self. Although age, gender and physical characteristics can also be altered in text-based online communication, these alterations take a visual representation in $3 \mathrm{D}$ environments. The physical appearance of virtual avatars affect the impressions formed about a character, but there are other impression management techniques in massive multiplayer environments such as nicknaming, demonstrating skill and power, power abusing and showing off (Jonsson, 2006). Even single player computer games like Elder Scrolls IV: Oblivion ${ }^{3}$, where no other human being other than the player himself forms impressions about himself, provides comprehensive visual customization techniques for the player character. The way one perceives oneself

\footnotetext{
${ }^{1}$ Assasin’s Creed II (2009) developed by Ubisoft.

2 Star Wars: Force Unleashed (2008) developed by LucasArts.

${ }^{3}$ Elder Scrolls IV: Oblivion (2006) developed by Bethesda Game Studios.
} 
also affects his gaming experience; the visual customization of the protagonist of the story gives the player the hero that he/she wants or fantasizes.

\subsection{PARTICIPATORY DESIGN}

Digital games allow for the emergence of participatory cultures where there the sender and the receiver roles become interchangeable. The distinction between the content creators (the games industry as the dominant culture) and the consumers (game players as the sub-culture) collapses, which is not typically associated with cinema-going or television viewing (Bryce and Rutter, 2006). This opportunity comes with tools or scripting languages shipped with computer games which allow players to alter any aspect of gameplay. This process is called game modding, which refers to the activity of making modifications to an existing commercial computer game's aesthetics, experience and structure. From a new media perspective, modding is a perfect example of migration from participatory culture to participatory design (Sotamaa, 2003) since it allows active gaming community members to modify/supply the content of the game. Although the high degree of technical competence demanded places modding practices out of reach of many gamers, game modding creates wider cultures, communities and rich contexts for criticism, review, and play, and modders are positively encouraged with tools, support and means of distribution by game developers (Newman, 2008).

\subsection{PRESENCE}

Presence is defined as the feeling of being there or the perceptual illusion of nonmediation (Lombard and Ditton, 1997). Filtering and organizing conflicting sensory data taken from the real and virtual worlds is an activity of selective attention and a subjective feeling. Immersion, which is frequently associated with presence in virtual environments, is a VR system's ability to deliver a surrounding environment, shutting out sensations from the real world (Slater and Wilbur, 1997). Factor analytic studies define involvement (Schubert et al. 2001) or engagement (Lessiter et al. 2001) as an important characteristic of presence, which represents a user's willingness to interact with the virtual environment (VE) and the significance or meaning he/she attaches to it. Heeter (1992) classified the concept into three components: personal presence, social presence, and environmental presence. Although game playing usually does not involve the use of special hardware such as head-mounted displays and position trackers that ensure physical presence by shutting down sensory information from the real world, the engaging and interactive experience of gameplaying can still invoke the sense of being transported to another reality. The player's ability to communicate interactively with other users or computergenerated agents within the virtual world creates a sense of social presence and the player's capability to change the virtual world by his or her actions represents environmental presence. 


\subsection{SOCIAL GROUPS}

Gaming websites, forums and mod repositories create virtual communities for gamers but designers also integrate smaller social groups within imaginary virtual worlds. Guilds, factions, religious orders and sects became an integral part of the social system. They usually consist of a group of PCs or NPCs that share their resources and buildings. The social system is built on a rank system, where higher-ranked player or non-player characters manage the organization and support the novice. In fact, by tying some of the game's activities to particular locations such as guilds or by designing quests too difficult for a single player to achieve, game designers are also encouraging the players to interact with other PCs and NPCs (Ducheneaut and Moore, 2004). To enhance sociability and to satisfy the player's need for affiliation, some NPCs were designed to join the player in his/her adventures. These characters, which are partially or fully controlled by the player, are called henchmen or followers. Players tend to form deep connections with these characters through shared adventure and dialogue (Christian et al. 2002). And some computer games (i.e., Might and Magic series ${ }^{4}$ ) do not even distinguish player character from these followers; they simply allow the player to begin the game with a group of characters. The player controls each one of them and acts as the single mastermind controlling the strategies or plans of the adventuring party. Given below is a figure that summarizes the concepts discussed so far and represents different interactivity levels in computer games.

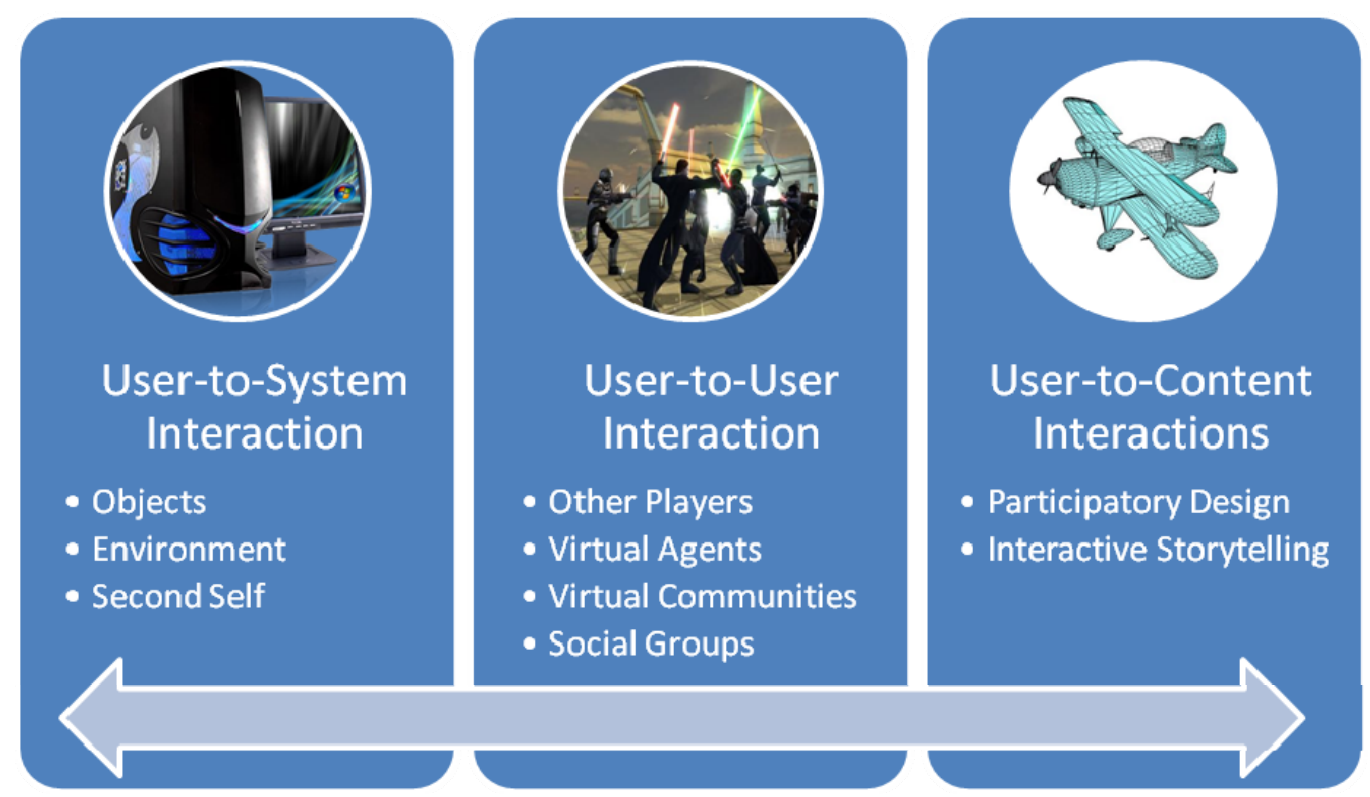

Figure 1: Different interactivity levels in computer games

\footnotetext{
${ }^{4}$ Might and Magic VI (1998), Might and Magic VII (1999), Might and Magic VIII (2000) and Might and Magic IX (2002), developed by New World Computing.
} 


\section{INTERACTIVE STORYTELLING SYSTEMS}

When it is difficult to define the general concept of interactivity, it becomes more problematic to define the notion of interactive storytelling. Cavazza et al. (2002) have drawn attention to the diversity of approaches in the field, such as: immersive storytelling, emergent storytelling, interactive authoring, plot-based systems, and character-based systems. Charles et al. (2003) defined the key problems in interactive storytelling as the trade-off between interactivity and storytelling, the duality between character and plot, narrative causality, the problem of narrative control, and the relations between story generation and presentation. Similar to the approaches employed and the problems identified by researchers, the focus of interactive storytelling systems is on the attributes of the technology or characteristics of the medium, such as the AI techniques, planning formalisms, story representations, etc., instead of the computer-mediated communication processes, such as the relatedness of transmitted messages with previous exchanges of information, the number of attributes to be manipulated by the player, or the level of player control on the messages.

User input or player interaction in a computer game usually comes in the form of mouse clicks or key presses that point to a specific location, an object or a virtual character in the gaming environment. Rafaeli (1988) defined three levels of interactivity: non-interactive, interactive or reactive, responsive or fully interactive. For example, in a computer game, if the game provides content without acknowledging the player's input, then it is noninteractive; if the game provides content that is a direct response to player's input, it can be considered as reactive. If the game responds in a manner that takes into account not only the latest input but the previous inputs of the player, then it can be considered as responsive. In this regard, interactive storytelling is more oriented towards a responsive, simultaneous and continuous message exchange which is based on player choices, preferences or playstyle. From our point of view, interactive storytelling is a gaming experience where the form and content of the game is modified in real time and tailored to the preferences and needs of the player to provide a sense of control over the mutual discourse of play. After all, the fundamental goal of interactivity is to allow the user different choices to be able to receive a highly personalized end result (Sundar, 2007).

\subsection{PROBLEMS OF INTERACTIVE STORYTELLING}

The most notable, maybe the most important criticism on interactive storytelling systems is expressed by Chris Crawford. According to Crawford (2005), interactive storytelling pays the price for the divide between scientists, engineers, and mathematicians (who are not just unschooled in the humanities but who actively dismiss the arts and humanities as soft-headed wastes of time) and the arts and humanities people (who simply refuse to have anything to do with the sciences and disparage science as "linear thinking"). If Chris Crawford is right about this divide then the notion of interactive storytelling has to be redefined. Game playing is a goal-directed behavior and a CMC process where the needs, motives and goals of the player interact with the opportunities, incentives and choices of the gaming environment and define the concept of "play". Thus, systems that just deal 
with the intelligent behaviours of virtual agents or the story planning approaches to get beyond branching narratives, without focusing on the psychology of the player, the enjoyment or the fun or the flow state experienced, and the communication processes inherent behind the information exchange, should find a more suitable name or concept for their proposed studies. In this regard, one of the best naming conventions, "automated storytelling", is invented by Nareyek (2007) who focuses on the automated generation of stories from a planning perspective.

\subsection{ARCHITECTURE OF INTERACTIVE STORYTELLING SYSTEMS}

The architecture of interactive storytelling systems usually include a "Drama Manager" (story engine, narrative generator, narrative logic, narrative sequencer, or plot manager), a "User Model" (player analyzer or player profiler), and an "Agent Model" (actor engine, knowledge base or behavior engine). The drama manager is responsible for searching and executing sequences of story plots (Bates, 1992; Kelso et al. 1993), sequencing story beats based on declarative knowledge (Mateas, 1997; Mateas, 2000; Mateas and Stern, 2001); generating stories according to the interaction between virtual actors with dramatic goals and the user (Cavazza et al. 2002), selecting, specifying and refining story events (Thue et al. 2007), selecting story beats based on a user model (El-Nasr, 2007), connecting dilemmas as points of interaction within a coherent plotline (Barber and Kudenko, 2008), partial ordering of abstract plot points (Magerko, 2005), ranking actions of characters from the most valuable to the least valuable (Szilas, 2003). The agent model focuses on believable characters showing autonomy, virtual actors with dramatic goals or semi-autonomous intelligent actors. The module or the component that keeps track of user interactions or choices is the user model or the player analyzer, but the diversity of the field is again reflected on how researchers profile players or how they define player types.

\subsection{PROFILING THE PLAYER: PLAY STYLES}

There have been many attempts to define play styles or player types of computer gamers. Bartle (2004) identified the famous four play styles as: socializers, achievers, killers and explorers; Salen and Zimmerman (2003) defined five player types: the standard player, the dedicated player, the unsportsmanlike player, the cheat \& the spoil-sport; Mulligan and Patrovsky (2003) introduced a grouping based on the relations between players: general players, barbarians, tribesman and citizens; Pohjola (2004), in the context of liveaction role-playing defined four categories: immersionist, dramatist, gamist, and simulationist; Dena (2008) defined the three tiers of hardcore gamers as: puzzle players, story players and real world players. These are general computer gamer categories that can be used to profile a player, but researchers are usually developing their own profiling techniques for interactive storytelling systems. In example, PASSAGE uses the player types of Peinado \& Gervas (2007): fighters, power gamers, tacticians, storytellers and method actors (Thue et al. 2007); IDA uses an internal probabilistic rule-based model (Magerko, 2005); Mirage uses personality traits that define a character stereotype (El-Nasr, 2007); Roberts et al. (2007) and Nelson et al. (2006) use an evaluation function of declarative optimization-based drama management (DODM) to present fully cooperative, 
partially cooperative and independent players. There are also other approaches which are not specific to interactive storytelling such as using game play schemas (Lindley and Sennersten, 2006) and scenarios (Ermi and Määyrä, 2004) for player modelling.

\section{PLAYER-CENTERED APPROACH TO INTERACTIVE STORYTELLING}

In $\mathrm{CMC}$ environments, meanings of information are determined by the receiver in a communication process and human feedback is the essential and critical element that controls the performance of a dynamical system (Huang, 2005). Similarly, different types of players attach different meanings to the intensive flow of information coming from the game world. In this sense, user-centered HCI or player-centered game design aims to dynamically adapt the gaming environment to the preferences of players to address the issues of ambiguity of information and user diversity. For adaptive gaming experiences, Wong et al. (2009) used self-organizing maps (SOMs) to cluster the player's style, Chiou and Wong (2008) proposed a Player Adaptive Entertainment Computing (PAEC) system that uses Neuro Linguistic Programming to model user satisfaction, and Rankin et al. (2008) discussed the components of user-centered game design for serious games. From our point of view, player modelling or profiling is the first step in dynamic reconfiguration of the virtual world to provide personalized gaming experiences. And the second step is in the player-centered approach to interactive storytelling is to decide on the parameters to be adapted or reconfigured beyond story plots and artificial intelligence capabilities of virtual agents. The term reconfiguration is transforming the "push button" interactivity into the productive process of gameplay where the user makes significant interventions into a game world to produce dynamic effects throughout the system (Dovey and Kennedy, 2006).

But the play styles or types of players defined in literature may not be sufficient for the profiling process. A single action pattern may satisfy two or more player needs (fusions), one or more needs may be activated in the service of another need (subsidiation of needs) and the needs may also contradict with each other (conflicts) (Murray, 1938). In this sense, player behaviour may exhibit very complex patterns in the game world. For example, Player A may wear an expensive trendy suit, because he/she does not wish to make a bad impression (Infavoidance) and instead wishes to win B's friendship (Affiliation), so that he/she will learn the secret location (Cognizance) of the celestial map and use the map for finding the lost city of Atlantis (Acquisition) to unlock the secrets of the Mother Civilization (Understanding) and thus level up (Achievement). In another example, if the player is exploring the whole virtual world, according to Bartle (2004), he/she is assumed to be an Explorer. But his/her motivation could be just to complete all the quests (Achievement), to acquire all unique items (Acquisition), to eliminate every single enemy (Agression) or could be all of them. Thus, a player model that takes into account motivations, underlying processes, personality traits, general behavior patterns and corresponding individual actions may yield better results in grouping player preferences. 


\subsection{TABLE-TOP RPGS AS INTERACTIVE STORYTELLING SYSTEMS}

Although the majority of the systems mentioned before focus on the drama manager or the story planning process, the "interactive" part of interactive storytelling is the user modelling or the player profiling that handles player interactions and defines how the story should be customized for the player. Based on play styles, character classes or player types, the drama managers usually customize the story plots or NPC goals. But the critical questions are "what" to customize, "how" to customize and "why" to customize. Are story plots or character interrelations the only elements to be customized to provide an interactive gaming experience? Are the aforementioned play styles or player types the only way to portray player preferences? And why is there a need for customization? This article believes that gameplaying experience should be customized for maximizing player enjoyment or providing an optimum gaming experience. The answers to "what" and "how" may lie in the analysis of table-top role playing games (RPGs), which are live counterparts of computerized interactive storytelling systems. These games are usually played with four to six players, which make up the adventuring party, and the one who controls the game is called the Dungeon Master (DM). The DM is the drama manager, player profiler and the agent modeler of these systems. How the DM handles the humanto-human communication process of interactive storytelling should give valuable insights on how to handle human-to-machine communication process of computerized systems.

Understanding table-top role playing games and the mechanisms behind them can be useful in enhancing the interactive gaming experience. In this regard, these games have also drawn the attention of interactive storytelling systems (Tychsen et al. 2005). Peinado and Gervás (2004) applied the game mastering laws used by a human DM controlling a role playing game to an automatic director for interactive digital storytelling applications. According to Louchart and Aylett (2003), participative forms of narrative such as table-top role-playing games, live role-playing games or improvisational theatre provide an interesting and entertaining narrative structure where control of the narrative is distributed between actors who use their dramatic experience to make choices. The accumulated knowledge of table-top role playing games has also influenced the design of computer role playing games (CRPG) which use rules or game mechanics based on their pen-and-paper equivalents. For example, developed by Wizards of the Coast (formerly TSR), Advanced Dungeons and Dragons or AD\&D is a game of imagination, as well as a game of tactics and strategy, which has set the standard for role-playing for more than 30 years. Indeed, the majority of the most successful CRPGs such as Baldur's Gate series ${ }^{5}$, Neverwinter Nights series ${ }^{6}$, Planescape Torment ${ }^{7}$, Icewind Dale series' ${ }^{8}$, Knights of the Old Republic series ${ }^{9}$ and Fallout ${ }^{10}$ series, use AD\&D system or its variants.

\footnotetext{
${ }^{5}$ Baldur's Gate (1998), Baldur's Gate II: Shadows of Amn (2000), both developed by Bioware.

${ }^{6}$ Neverwinter Nights (2002) developed by Bioware, Neverwinter Nights II (2006) developed by Obsidian Entertainment.

${ }^{7}$ Planescape Torment (1999) developed by Black Isle Studios.

${ }^{8}$ Icewind Dale (2000), Icewind Dale II (2002), both developed by Black Isle Studios.

${ }^{9}$ Knights of the Old Republic (2003) developed by Bioware, Knights of the Old Republic II: Sith Lords (2005) developed by Obsidian Entertainment.
} 
Dungeon Masters of table-top role-playing games not only determine the story plots for their adventures, but also customize the geography, regional history, life and society of the virtual world, the abilities, skills, items and personality of the virtual characters, and the rewards they will give at the end of quests. Another task of the DM is to balance the game challenges or difficulty levels for all players to provide the best level of satisfaction without frustrating them. All these customizations are based on character classes (fighter, rogue, wizard, etc.), character alignment (chaotic good, neutral evil, lawful neutral, etc.), skills, feats and special abilities of the characters that define their play style, and their psychological needs or motivations. For example, adventures that take place in evil aligned planes (Abyss, Acheron, Baator, etc.) should be more difficult for good-aligned adventurers since the plane itself is hostile towards them. If this is their first planar adventure, the rewards given to the players should help them to survive and to get accustomed to the environment. Thus, fighters should be given magical weapons capable of inflicting damage on planar enemies and wizards should be given items that will render their spells more effective and powerful. And of course, encounters involving evil outsiders are more difficult without a paladin or cleric in the group, and magic resistances of enemies and wild/dead magic areas in the environment make things more difficult for wizards. The customizations can even extend to fulfilling the romantic needs of the paladin of the group who constantly yearns for a lover. All these are considerations for the DM when running a game.

\subsection{COMPUTER RPGS AS INTERACTIVE STORYTELLING SYSTEMS}

The same customization trends can also be seen in CRPGs. Official AD\&D titles generally use character alignment to customize the story structures. Knights of the Old Republic series use a similar distinction of characters, the dark side (Sith) and the light side (Jedi). Other than character alignment based on three axes (good-neutral-evil), some titles are more interested in what the character stands for or whom he/she sides with in a world of conflict and intrigue. Morality of characters in Mass Effect ${ }^{11}$ is divided into two: "Paragon" for choosing professional military actions or "Renegade" for taking a more ruthless approach. The Witcher ${ }^{12}$ determines three primary paths for the story: the Scoiatael path, the Order path and the neutral path. The protagonist of the story Geralt can side with the Elves or the Order, but can also stay neutral. Based on Geralt's choices in the game, the virtual world, the characters inhabiting it and the way characters treat the player is thoroughly customized. Player choices can also be reflected on the player character's appearance. The ethical decisions players make in Fable13 affect how players are perceived by others, but also have a visual impact on their appearance. Reward customization is accomplished by placing special items in the game world which can only be used by certain classes, characters with particular skills or alignment. But the game engine usually

\footnotetext{
${ }^{10}$ Fallout (1997), Fallout 2 (1998), both developed by Black Isle Studios, Fallout 3 (2008) developed by Bethesda Game Studios.

${ }^{11}$ Mass Effect (2007) developed by Bioware.

12 The Witcher (2007) developed by CD Project.

${ }^{13}$ Fable (2004) developed by Lionhead Studios.
} 
does not intervene in the process of reward giving, all these items are scattered throughout the world, the play may or may not find them. And the game difficulty of CRPGs is usually adjusted dynamically to match the skills and abilities of the player. In this regard, there are five different gaming components which can be customized in three different levels.

\subsection{PSYCHOLOGY OF THE PLAYER: GAMING MOTIVATIONS}

Beyond character alignment and play styles, profiling the player based on his/her needs or motivations is still a theoretical concept which can not be found in commercial video games, but in research prototypes. There have been attempts to define the underlying motives of players but even the major studies in this area (Malone and Lepper, 1987; Sweetser and Wyeth, 2005; Yee, 2006) can not reach to an agreement on common motivational variables. Different approaches to motivational aspects of player behavior when applied to computer games with different structures and content should obviously represent different facets of player psychology. In an attempt to define a broader range of motivational variables based on formal theories of human motivation, Bostan (2009) proposed a motivational framework based on the psychological needs of Murray (1938), analyzing player needs in relation to the gaming situations of a CRPG. The study defined motivation as a product of continuous interactions between players and the virtual world, each individual psychological need is briefly described in terms of the actions it provokes. In an attempt to take this study one step further and to identify the common interaction patterns of players, the same motivational framework was applied to another CPRG and the individual needs were analyzed by defining the driving game mechanics behind them (Bostan and Kaplancal1, 2009). Since Murray (1938) defined each need with appropriate desires and effects, matching actions, feelings, emotions, personality traits, and common relationships with other needs such as fusions or conflicts, this framework could lead to a whole new set of opportunities for analyzing gameplaying preferences and entertainment experiences.

This study focuses on the six categories of needs defined by Bostan (2009). In summary, there are four materialistic needs representing Acquisitive, Constructive, Orderly, Retentive attitude, six power needs representing Aggressive, Blamavoidant, Counteractive, Defendant, Deferent, Dominative attitude, five affiliation needs representing Abasive, Affiliative, Nurturant, Rejective, Succorant attitude, six achievement needs representing Achievant, Autonomous, Fearful, Infavoidant, Self-forwarding, Exhibitionistic attitude, three information needs representing Inquiring, Informing, Intellectual attitude, and three sensual needs representing Playful, Sentient, Erotic attitude.

\subsection{MONITORING PLAYER ACTIONS THROUGHOUT THE GAME}

Customization of the gaming experience requires constant monitoring of the player actions within the virtual world. Player actions shall give an idea about his/her preferences or needs, but it should not be forgotten that the restrictions imposed by the game mechanics significantly reduce the number of player needs satisfied by a game. For 
instance, if a quest requires the player to kill an opponent when he/she has no other option, then the act of killing cannot be considered inclination towards aggressive behavior. It can be considered so only when the player has other options. For example, in popular CPRG titles, the player usually notices the enemies before the enemies notice the player, and it is up to the player how he/she overcomes obstacles. Some alternatives are to ignore the enemy by sneaking from a safe distance (Harmavoidance), to directly attack the enemy with a weapon of choice (Aggression) or to sneak to a favorable position and eliminate the enemy quickly taking advantage of surprise and without receiving much damage in the process (Aggression+Harm Avoidance). It is these choices in a computer game that determine the play style of a player and indicate his/her trends in motivation. But the player's actions before the choice are also important determinants for understanding his/her motivations of the player. If the player is low in health and ammunition before the choice, it is understandable why he/she avoids a powerful group of monsters (Harmavoidance inhibiting Aggression). And, the actions after the enemy is eliminated are also indicators of player intent. One who loots every single enemy after the combat (Acquisition) is not like the one who ignores the dead bodies and proceeds to his/her next quest destination (Achievement). And even one who loots and retains possession of every single item (Retention) is satisfying different needs than one who only loots ammo/weapons (Aggression).

\subsection{CUSTOMIZING EXPERIENCE, SATISFYING PLAYER NEEDS}

Let's assume that there is a player that is more oriented towards the needs of Affiliation, Harmavoidance, Sentience, Cognizance and Sex. This player likes to form friendships or associations, avoids physical injury if possible, delights in the beauty of his/her own body and enjoys sensuous imagery, enjoys gathering/seeking information and forming erotic/romantic relationships. Players high in Sentience also attracted by pleasurable sights (color, light, form, pose, movement, a beautiful face, clothes, etc.) and they seek variety in these sensuous impressions. It should not be forgotten that, some matching personality traits for the needs of Affiliation, Harmavoidance, Sentience, Cognizance and Sex are (Murray, 1938): affiliative, cooperative, friendly, attentive to danger, cautious, aesthetic, open to new experience, curious and seductive. Once this player's preferences and motives were understood, it is possible to proceed to customizations for this type of player.

Story: It is obvious that encounters with monsters that utilize a simple fight/eliminate/loot sequence are not appropriate for this type of player. The story should be customized with social encounters rather than aggressive encounters where the player is given peaceful solutions to oppositions by negotiating, exchanging information or seducing. For example, a world of intrigue and sex where knowledge and passion rules the order suits very well for this type of player. This can easily be achieved by inserting a guild, cult or secret organization into the story. And to satisfy the need of self-representation, the player should be given opportunities to customize his/her physical appearance and emphasize his/her physical beauty. 
Virtual World: The physical appearance of the virtual world should have rich components of color, shading, light, form and pose to satisfy the need for sentience. Satisfaction of the need for affiliation is possible with a virtual world that provides socially rich environments with guilds or NPC characters that become party members (henchmen or followers). Players are known to form deep connections with guild members or followers through shared adventure and dialogue (Christian et al. 2002). To satisfy the need for harmavoidance, the virtual world should also have shrines or resting points where the player can rest and heal his/her injuries.

Virtual Agents: NPCs should include opposite sex characters that shows an interest in the player character and wishes to form romantic relationships with him/her through dialogue choices and/or quests. These characters should wear eye-catching clothes and should be physically attractive. Merchant characters that sell healing potions, salves, clothing and apparel are very important for this type of player. Since the player also enjoys gathering/seeking information, information dealers or informants will attract the player.

Difficulty: Adjusting the difficulty levels of creatures or combat parameters is not suitable for this type of player. Memory/knowledge challenges that require the players to know certain facts and remember them throughout the game or cleverness/ logic challenges that test the player's intelligence with puzzles are more suitable for this type of player. For an optimum gaming experience, the game should provide believable memory/knowledge and cleverness/ logic challenges that match the skills of the user and do not restrain the sense of achievement (Bostan and Ogut, 2009).

Rewards: And rewards suitable for this type of player are: potions or elixirs that heal wounds or render the player invisible in combat, bits and pieces of information in the form of scrolls or books that can be collected/analyzed by the player, pieces of clothing in different forms, styles and color that increase the attractiveness of the player character. 


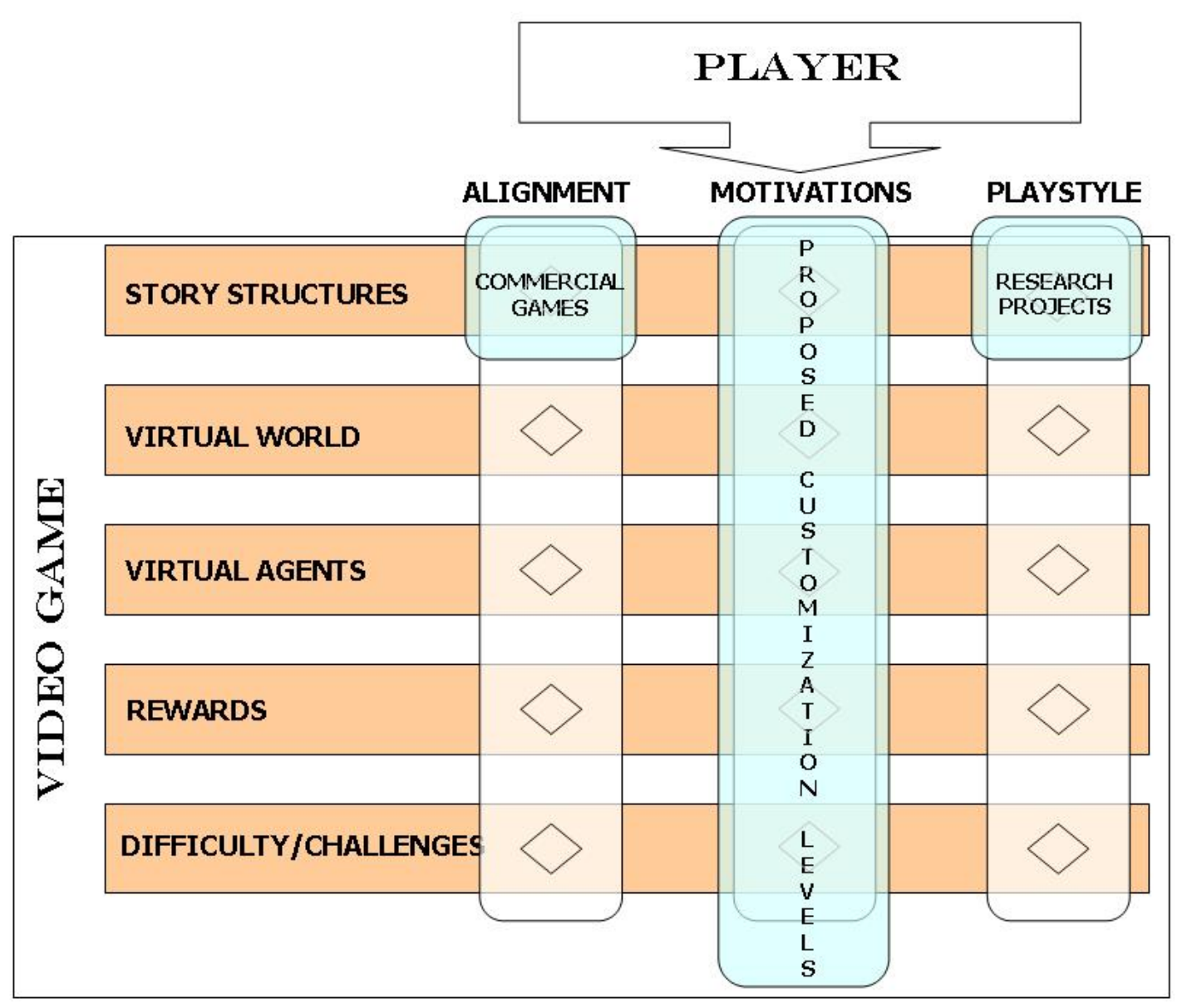

Figure 2: Proposed customization levels for interactive storytelling systems

\section{CONCLUSION}

Interactive storytelling is not only about providing intelligent virtual agents or planning story structures to get beyond branching narratives, it is a player-centered design process that focuses on the psychology of the player, his/her needs, the enjoyment or the fun or the flow state experienced. It may not be possible to make customizations on all the proposed levels, but popular CRPGs demonstrated that it is even possible to satisfy players by customizing some of the proposed levels without even touching at the story structures. For example, characters that join the player in Baldur's Gate II: Shadows of Amn (one of the most popular CRPG titles) all have different backgrounds and distinctive personalities, and it is their phrases, arguments, and battle cries that obtain the player's loyalty. It is surprising to see that people still remember NPCs from Baldur's Gate II, which was released in September, 2000. It is possible to find groups devoted to Baldur's Gate II characters in social networking websites such as Facebook. The game customized numerous henchmen NPCs (both evil and good) for the player and the unique gaming experience provided by the game can still be remembered after 10 years. 
The diversity of player needs is also reflected on the game mods created for games. Game modding refers to the activity of making modifications to an existing commercial computer game's aesthetics, experience and structure. From a motivational perspective, game modding is a convenient way of satisfying user needs that are not fulfilled by the game itself. If a human need is a condition marked by the lack of something, game mods are also marked by the lack of something or missing feature in a computer game. The modifications in the game mechanics allow the user to break the constraints imposed by the game, thus providing an opportunity to satisfy his/her broader range of needs. A recent study attempted to find the current trends in user created content for role-playing games (RPGs) and discussed the implications of game modding in identifying the missing features of an entertainment experience and of investigating the player motivations (Bostan and Kaplancall, 2010). Although the restrictions imposed by the game mechanics significantly reduce the number of player needs satisfied by a game and trap the player within the common motivational cycle of Achievement, Aggression, Harmavoidance and Acquisition (Bostan and Kaplancall, 2009), the mentioned study shows that the game mods created by users attempt to compensate for this by satisfying the needs of Sentience, Exhibition, Recognition, Sex, Play and Affiliation (Bostan and Kaplancal1, 2010). In this regard, interactive storytelling systems should also focus on satisfying a broader range of player needs by customizing the content of the game.

The motivational framework discussed in this study provides a convenient way of understanding player preferences and also defines our method of "how" to modify the different levels of customization discussed in the previous sections. In the previous section, it is assumed that there is a player who is more oriented towards the needs of Affiliation, Harmavoidance, intraSentience, Cognizance and Sex. Is it possible to classify this player if an interactive storytelling system is using player types defined by previous studies? Is this player an immersionist, a dramatist, a gamist or a simulationist? Or is he/she a socializer, an achiever, a killer or an explorer? It can be argued that he/she is more a socializer type, but players usually explore the majority of the virtual world to find different opportunities to gratify different needs and they aim for achieving maximum levels to better satisfy them. So, how do we separate it from an achiever or an explorer? The player types used in an interactive storytelling system are crucial in the whole process since the drama manager takes into account these pre-defined types and customizes/plans stories that will maximize enjoyment for these groups of players. Thus, this article proposes a broader range of variables composing of various psychological needs. The number of player types or play styles that can be defined with this framework is virtually limitless but in this regard this article is not concerned with the number of distinct profiles, it focuses on customization of game content on five different levels (story structures, virtual world, virtual agents, rewards, difficulty) to satisfy each individual player need. 


\section{REFERENCES}

Barber, H. and Kudenko, D. (2008). Generation of Dilemma-based Interactive Narratives with a Changeable Story Goal, in: Proceedings of Second International Conference on Intelligent Technologies for Interactive Entertainment (INTETAIN).

Bartle, R.A. (2004). Designing Virtual Worlds. New Riders Publishing.

Bates, J. (1992). Virtual Reality, Art, and Entertainment. Presence: Teleoperators and Virtual Environments, 1 (1), 133-138.

Blanchard, A. and Markus, M.L. (2004). The experienced 'sense' of a virtual community: characteristics and processes. Database for Advances in Information Systems 35 (1), 6579 .

Bostan, B. (2009). Player Motivations: A Psychological Perspective. ACM Computers in Entertainment 7 (2), 22:1-22:26.

Bostan, B., and Kaplancali, U. (2009). Explorations in Player Motivations: Game Mechanics, in: Proceedings of GAMEON 2009, Duesseldorf, Germany.

Bostan, B., and Kaplancali, U. (2010). Explorations in Player Motivations: Game Mods, in Proceedings of GAMEON-ASIA 2010 Conference, Shanghai, China.

Bostan, B., and Ogut, S. (2009). Game Challenges and Difficulty Levels: Lessons Learned From RPGs, in Proceedings of ISAGA 2009 Conference, Singapore.

Bryce, J. and Rutter, J. (2006). Understanding Digital Games. London: Sage.

Castranova, E. (2007). Exodus to the Virtual World: How online fun is changing reality. New York: Palgrave Macmillan.

Cavazza, M., Charles, F., and Mead, S.J. (2002). Interacting with Virtual Characters in Interactive Storytelling, in: Proceedings of the First ACM Joint Conference on Autonomous Agents and MultiAgent Systems, Bologna, Italy, pp. 318-325.

Charles, F., Lozano, M., Mead, S.J., Bisquerra, A.F., and Cavazza, M. (2003). Planning Formalisms and Authoring in Interactive Storytelling, in: Proceedings of TIDSE'03: Technologies for Interactive Digital Storytelling and Entertainment, Darmstadt.

Chiou, A. and Wong, K.W. (2008). Player Adaptive Entertainment Computing (PAEC): Mechanism to Model User Satisfaction by Using Neuro Linguistic Programming (NLP) Techniques, in: Proceedings of 2008 IEEE Symposium on Computational Intelligence and Games, Perth, Australia, 343-349. 
Christian, D.B., Riedl, M.O.,and Young, R.M. (2002).Conversation starters: Using spatial context to initiate dialogue in first person perspective games, in: Proceedings of the 2002 AAAI Spring Symposium on Artificial Intelligence and Interactive Entertainment.

Crawford, C. (2005). Chris Crawford on Interactive Storytelling. New Riders.

Csikszentmihalyi, M. (1990). Flow: The Psychology of Optimal Experience. Harper Perennial.

Dena, C. (2008). Emerging Participatory Culture Practices: Player-Created Tiers in Alternate Reality Games. Convergence: The International Journal of Research into New Media Technologies, 14, 41-57.

Dovey, J. and Kennedy, H.W. (2006). Game Cultures: Computer Games as New Media. Open University Press, Maidenhead \& Milton Keynes.

Ducheneaut, N. and Moore, R.J. (2004). The social side of gaming: A study of interaction patterns in a massively multiplayer online game, in: Proceedings of the 2004 ACM Conference on Computer Supported Cooperative Work, New York.

El-Nasr, M.S. (2007). Interaction, Narrative, and Drama Creating an Adaptive Interactive Narrative using Performance Arts Theories, Interaction Studies 8 (2), 209-240.

Ermi, L., and Määyrä, F. (2004). Player-Centred Game Design: Experiences in Using Scenario Study to Inform Mobile Game Design, in: Game Design Research Symposium and Workshop, Copenhagen.

Heeter, C. (1992). Being there: The subjective experience of presence. Presence: Teleoperators and Virtual Environments 1 (2), 262-271.

Heim, M. (1998). Virtual Realism. Oxford University Press, New York.

Huang, S-C. (2005). Semiotics and Information Theory: The Value of User-Centered Approach and a Theoretical Framework of Human-Computer Interaction Design for Computer-Mediated Communication, Master Report presented to the Graduate School of University of Texas at Austin.

Jensen, J.F. (1998). Interactivity: Tracing a New Concept in Media and Communication Studies. Nordicom Review, 19 (1), 185-204.

Jonsson, F. (2006). Performing the Self in Cyberspace: A study of Young Players Styles of Self-Presentation and Identity Performances, in: The Online Game World TIBIA, 9th Nordic Youth Research Information Symposium, Stockholm.

Kelso, M., Weyhrauch, P., and Bates, J. (1993). Dramatic Presence. Presence: The Journal of Teleoperators and Virtual Environments, 2 (1), 1-15. 
Kraut, R., Kiesler, S., Boneva, B., Cummings, J.N., Helgeson, V., and Crawford, A.M. (2002). Internet paradox revisited. Journal of Social Issues 58 (1), 49-74.

Kraut, R., Patterson, M., Lundmark, V., Kiesler, S., Mukophadhyay, T., and Scherlis, W. (1998). Internet paradox: A social technology that reduces social involvement and psychological well-being? American Psychologist 53 (9), 1017-1031.

Lessiter, J., Freeman, J., Keogh, E., and Davidoff, J. (2001). A Cross-Media Presence Questionnaire: The ITCSense of Presence Inventory. Presence: Teleoperators, and Virtual Environments 10 (3), 282-297.

Lievrouw, L. and Livingstone, S. (Eds.). (2002). Handbook of New Media: Social Shaping and Social Consequences. London: Sage.

Lindley, C.A., and Sennersten, C. (2006). Game Play Schemas: From Player Analysis to Adaptive Game Mechanics, in: Joint International Conference on CyberGames and Interactive Entertainment (CGIE2006), Special Session on Game Artificial Intelligence, Perth, Western Australia.

Lombard, M. and Ditton, T. (1997). At the heart of it all: The concept of presence. Journal of Computer Mediated-Communication 3 (2), [online]. Available from:

http://jcmc.indiana.edu/vol3/issue2/lombard.html.

Louchart, S., and Aylett, R. (2003). Towards a narrative theory of virtual reality. Virtual Reality 7 (1), 2-9.

Magerko, B. (2005). Story Representation and Interactive Drama, in: Proceedings of the 1st Conf. On Artificial Intelligence and Interactive Digital Entertainment.

Malone, T.W., and Lepper, M.R. (1987). Making learning fun: A taxonomy of intrinsic motivations for learning, in: Snow, R.E., and Farr, M.J. (Eds.), Aptitude, Learning, and instruction: Conative and Affective Process Analyses, Lawrence Erlbaum, Hillsdale, NJ, pp. 223-253.

Mateas, M. (1997). An Oz-Centric Review of Interactive Drama and Believable Agents, in: AI Today: Recent Trends and Developments. Lecture Notes in Artificial Intelligence 1600, pp. 297-328.

Mateas, M. (2000). A Neo-Aristotelian Theory of Interactive Drama, in Proceedings of AAAI Spring Symposium on AI and Interactive Entertainment.

Mateas, M., and Stern, A. (2001). Interactive Drama. A Thesis Proposal, Ph.D. thesis, Pittsburgh, Carnegie Mellon University. 
McMillan, S. (2002). Exploring models of interactivity from multiple research traditions: users, documents and systems, in: Lievrouw, L. and Livingstone, S. (Eds), The handbook of the new media. The social shaping and consequences of ICTs. London: Sage, pp. 163-182.

Mulligan, J. and Patrovsky, B. (2003). Developing Online Games. An Insider's Guide. Indianapolis, IN: New Riders.

Murray, H.A. (1938). Explorations in Personality. Oxford University Press.

Nareyek, A. (2007). Game AI is Dead. Long Live Game AI! IEEE Intelligent Systems, 22 (1), 9-11.

Nelson, M.J., Roberts, D.L., Isbell, C.L., and Mateas, M. (2006). Reinforcement Learning for Declarative Optimization Based Drama Management, in: Proceedings of the Fifth International Joint Conference on Autonomous Agents and Multiagent Systems (AAMAS).

Newman, J. (2008). Playing with Videogames. London: Routledge.

Peinado, F., and Gervas, P. (2004). Transferring game mastering laws to interactive digital storytelling, in: 2nd International Conference on Technologies for Interactive Digital Storytelling and Entertainment (TIDSE 2004), Darmstad, Germany: Springer, 1-12.

Peinado, F. and Gervás, (2007). P. Automatic Direction of Automatic Storytelling: Formalizing the Game Master Paradigm, in: Proceedings of the 4th International Conference on Virtual Storytelling: Using Virtual Reality Technologies for Storytelling (ICVS).

Pohjola, M. (2004). Autonomous Identities: Immersion as a Tool for Exploring, Empowering and Emancipating Identities, in: Montola, M., and Stenros, J. (Eds.), Beyond Role and Play: tools, toys and theory for harnessing the imagination. Ropeconry, Helsinki, pp. 81-96.

Rafaeli, S. (1988). Interactivity: From New Media to Communication, in: Hawkins, R.P., Wiemann, J.M., and Pingree, S. (Eds.) Advancing Communication Science: Merging Mass and Interpersonal Processes. Newbury Park, CA: Sage, pp.110-134.

Rafaeli, S. and Ariel, Y. (2007). Assessing Interactivity in Computer-Mediated Research, in: Joinson, A.N., McKenna, K.Y.A., Postmes, T., and Rieps U.D. (Eds.). The Oxford Handbook of Internet Psychology. Oxford University Press, pp. 71-88.

Rankin, Y.A., McNeal, M.,. Shute, M.W, and Gooch, B. (2008). User centered game design: evaluating massive multiplayer online role playing games for secondary language acquisition, in: Proceedings at the ACM SIGGRAPH, 43-49. 
Roberts, D.L., Strong, C.R., and Isbell, C.L. (2007). Using Feature Value Distributions to Estimate Player Satisfaction Through an Author's Eyes, in: Proceedings of the AAAI 2007 Fall Symposium on Intelligent Narrative Technologies.

Rogers, C. (1951). Client-centered therapy, Boston, MA: Houghton-Mifflin.

Rogers, E.M. (1986). Communication Technology. Free Press, New York.

Salen, K. and Zimmerman, E. (2003). Rules of Play: Game Design Fundamentals, Cambridge, MA: The MIT Press.

Schreiber, M., Wilamowitz-Moellendorff, M.V., and Bruder, R. (2009). New Interaction Concepts by Using the Wii Remote, in: Proceedings of Human-Computer Interaction, Novel Interaction Methods and Techniques, 13th International Conference, Part II, pp. 261270.

Schubert, T., Friedman, F., and Regenbrecht, H. (2001). The experience of presence: Factor analytic insights. Presence: Teleoperators, and Virtual Environments 10 (3), 266-281.

Sellers, M. (2006). Designing the experience of interactive play, in: Vorderer, P., Bryant, J. (Eds.). Playing video games: Motives, responses, and consequences. Mahwah, NJ: Lawrence Erlbaum, pp. 9-22.

Shedletsky, L., and Aitken, J. (2004). Human Communication on the Internet. Boston, MA: Allyn \& Bacon/Longman.

Slater, M. and Wilbur, S. (1997). A framework for immersive virtual environments (FIVE): Speculations on the role of presence in virtual environments. Presence: Teleoperators and Virtual Environments 6 (6), 603-616.

Sotamaa, O. (2003). Computer game modding, intermediality, and participatory culture, in Proceedings of New Media? New Theories? New Methods? Innovating Media and Communication Research, [online]. Available from:

http://old.imv.au.dk/eng/academic/pdf_files/Sotamaa.pdf

Szuprowicz, B. (1995). Multimedia networking. New York: McGraw-Hill.

Steuer, J. (1992). Defining virtual reality: Dimensions determining telepresence. Journal of Communication 42 (4), 73-93.

Sundar, S.S. (2007). Social psychology of interactivity in human-website interaction, in Joinson, A.N., McKenna, K.Y.A., Postmes, T., and Rieps, U.D. (Eds.), The Oxford Handbook of Internet Psychology. Oxford University Press, pp. 89-102. 
Sweetser, P., and Wyeth, P. (2005). GameFlow: A model for evaluating player enjoyment in games. ACM Computers in Entertainment 3 (3), 1-24.

Szilas, N. (2003). IDTension: A Narrative Engine for Interactive Drama, in: Proceedings of the Technologies for Interactive Digital Storytelling and Entertainment (TIDSE) Conference, 187-203.

Thue, D., Bulitko, V., Spetch, M., and Wasylishen, E. (2007). Interactive Storytelling: A Player Modelling Approach, in: Proceedings of Artificial Intelligence and Interactive Digital Entertainment Conference (AIIDE), Stanford, California, 43-48.

Turkle, S. (1984). The Second Self: Computers and the Human Spirit. Simon \& Schuster, New York.

Tychsen, A. Hitchens, M., Brolund, T., and Kavakli, M. (2005). The Game Master, in: Proceedings of the Interactive Entertainment Conference, Sydney, Australia, 215-222.

Wong, C., Kim, J., Han, E., and Jung, K. (2009). Human-centered modeling for style-based adaptive games, Journal of Zhejiang University-Science A 10 (4), 530-534.

Yee, N. (2006). Motivations of play in online games. CyberPsychology E Behavior 9 (6), $772-$ 775. 